\title{
Chloramphenicol Sodium Succinate
}

National Cancer Institute

\section{Source}

National Cancer Institute. Chloramphenicol Sodium Succinate. NCI Thesaurus. Code C47972.

The sodium succinate salt form of chloramphenicol, a nitrobenzene derivate and broadspectrum antibiotic with antibacterial activity. Chloramphenicol sodium succinate reversibly binds to the $50 \mathrm{~S}$ subunit of bacterial ribosomes, thereby interfering with peptidyl transferase activity in the elong ation process of protein synthesis. As a result, this agent prevents bacterial cell growth. 